\title{
Study on Construction of Public Sports Service System Demonstration Plot of China \\ ----A Case of Wujin District of Changzhou City

\author{
Dongjin Xian
}

Institute of Physical Education of Changzhou University, Changzhou, Jiangsu, China, 213164

Xdj@cczu.edu.cn

Keywords: Sport Service System; Sport Building Area; Sport Brand; Construction of Demonstration Plot

\begin{abstract}
By looking up document literature and logical analysis, the author analyzes the construction of public sports service system demonstration plot of Wujin district of Changzhou to understand its construction standards and content system. The research shows that the plot adopts the form of leading by government, coordinates with relative departments, participates in the whole society, and guides itself with non-profit, equality and convenience. The system concludes the following respects: 10-mins sports area, government purchasing public sport service, the construction of grass-root sport institutions, opening school sport facilities to public, build ing city's sport brand by holding great sport event and improving the quality of grass-root cadre.
\end{abstract}

\section{Introduction}

After holding Beijing Olympic Games successfully in 2008, the development sports cause of China faces a new start. At the Awards meeting of Beijing Olympic Games and Paralympic Games, general secretary Hu Jintao set the goal of shifting China from a big sport nation to a strong one, giving a clear forward direction of sport development. The "Twelfth Five-year" Plan of Sport Cause Development by the General Administration of Sport of China shows that China should accelerate improvement of public sport service system, increase service level of public sports to improve physics quality and health care of the whole nation and promote the sports development of common people to a new stage. Based on this opportunity, Liu Peng, Director of State General Administration of Sport, on behalf of General Administration of Sport, signed the "Cooperative Agreement on Construction of Public Sports Service System Demonstration Plot between General Administration of Sport and the People's Government of Jiangsu Province" with Li Xueyong, governor of Jiangsu Province on Dec.31, 2013. The two parties will coordinate with each other to construct the plot. This paper aims at searching Wujin's model for surrounded cities to build a scientific and efficient system by researching public sports service system in Wujin district.

\section{The Construction Standard of Public Sport Service System in Wujin District}

The "Cooperative Agreement on Construction of Public Sports Service System Demonstration Plot between General Administration of Sport and the People's Government of Jiangsu Province" (hereinafter referred to as the "Agreement"), will improve the contents of public sports service through a new cooperative way of province and ministry. According to the agreement, General Administration of Sport of China will reinforce the construction of public sports facilities, host of activities and establishment of institutions in Jiangsu province and help it make basic construction plan, service standard and evaluate the performance. People's government of Jiangsu province strengthens further the project design of basic sports service system plan, as well as its standard and government investment and performance evaluating, and accelerate the speed of building the system with the characteristics of bright features, perfect function and the integration of cities and towns. According to 
the instruction of the "Agreement", in the first half year of 2014, the government of Wujin District will advance "The Public Sports Service System Implementation Plan of Wujin District", "The Urban and Rural Construction Plan of 10-mins Sports Areas in Wujin District", "The Document about Target Construction Assignment of Public Sports Service System in 2014”. These papers make kind of plans, assignments and goals clear, and guarantee the construction of the demonstration plot smoothly. According to governor Li Xueyong, the construction of demonstration plot insists on putting people in the first place, innovating institution and mechanism, promoting overall plan of cities and towns, increasing service guarantee, and accelerating construction of the system with clear function, complete network, integration of cities and towns and benefit to all people, the project is of non-profit, fundamentality, equality and convenience, centers on perfecting facilities, promoting sharing, innovating pattern, enriching content and improving quality, forms a widely covered, and well constructs public sports service system to meet people's need of urban and rural place. Public sports facilities construction will be strengthened to fulfill the goal of opening big public sports field to society, giving privilege to the old people and the teenagers as well as the disabled people, the service is free of charge on the physics day on 8th of August; the grass-root public sports facilities, such as streets, committee, towns (villages) and outdoor track and field, basketball field, are also open to people for free and the opening time should be out of working time. Perfecting governing system of the sports facilities opening to society of units such as schools, institutions and enterprises, well -conditioned schools should open their sports facilities to society to fulfill the goal that the available public sports field (school field are conclude) count 55 percent or more of the whole place, and school sports facilities opening rate is up to 95 percent. The plot will fully implement the national fitness plan, complete grass-root overall fitness institution service system to give the Chinese people bodybuilding guide, encourage them to join in bodybuilding activities, educate our people with scientific bodybuilding knowledge, and provide bodybuilding equipment and bodybuilding areas such as parks and grassy areas to them. The demonstration plot will help to build grass-root sports club, teenager sports club and sports station. In addition, the plot will enlarge the number of guiders of social physics to distribute 20 guides to each 10 thousand people, holding the national fitness volunteer service activities vigorously. Full implementation of the urban and rural construction of 10-mins sports areas has been listed to prior goal of serving people project of Wujin District government in 2014. The plot will advance standard construction of cities and towns, popularize Radio calisthenics and exercises before or between working time and other bodybuilding means, broadly carry out rich and public-oriented activities, and deeply conduct "sports getting into the offices, into the enterprises, into the communities" activities to bring sports into common life. Establish guiding station to measure physics quality and guide bodybuilding activities, impart scientific fitness knowled ge to help people exercise appropriately, and carry out activities accord ing to the exercising standard, examine students' physics quality strictly, commit physical quality measuring standard of handicapped people and test people at regular time.

\section{Constitutions of Public Sports Services System of Wujin District}

According to the requirement of the demonstration plot, Wujin District will further optimize the allocation of public sports service facilities and correctly arrange the priority sequence of the construction of public sports service system to give people access to public sports services, mak ing the service convenient to people. So far, Wujin District has made great progress in these respects.

Comprehensively Carrying out the Urban and Rural Construction of 10-mins Sports Areas. Wujin District has carried out the activities of "10-mins sports area" as early as in 2010, and till 2013, Wujin Dstrict has basically established the sports fitness areas in the city center and passed the test of Jiangsu province. Among them, Hutang town has fully established the fitness areas in 44 committees, the areas of the other towns are also under construction, there are 96 newly established or rebuilt sports places in this district, newly added more than 1.3 million square meters to build sports place, the school 
sports area opening rate has been to 90 percent, and per capita area of public sports facilities in the whole district is up to 3.2 square meters. In 2014, in order to reinforce the construction of 10-mins sports areas, Wujin District will build 15 demonstration communities for 10-mins sports areas, 4 city-level body-building demonstration projects of in the whole district to lift the level of this item, build 4 national activity centers in Qianhuang town, Huangli town, Niutang town and Lijia town, set up 50 national fitness activities stations and completely renew these equipment when they are out of use, and do well in the management of fitness equipment maintenance. Up to 2015, according to the demonstration plot construction standards of public sports service system of Jiangsu province, every town (street) should be demonstration town (street), the villages or committees should make more than 90 percent of their villages or towns become demonstration villages or towns in 2014, and fully establish demonstration villages or towns in 2015.

Public Sports Services Procurement by the Government. In recent years, Wujin District has purchased public sports services with governmental finance and applied management supporting and commission and franchise chain shop operation, to put the civil fitness center into the charge of the management company, making great profit both in society and economy. In 2014, Wujin District spent more fund on purchasing public sports services and invited public bid for the project of public sports services to attract social power into the construction of public sports services and to enrich public product supply. On March 19 and 20 of the year, the Sports Bureau of Wujin District held conference before the bidding on "fitness-oriented logo" and "public service project of civil fitness facilities", with the total investment fund up to 2.5 million Yuan. 11 enterprises signed up for the bid of "fitness-oriented logo", of which there were 8 local companies of Changzhou City and 3 from other cities; 5 enterprises signed up for the bid of "public service project of civil fitness facilities developed by Wujin District Sports Bureau of Changzhou".

Construction of Sports Organizations at Grass-root Level. The diversity of community sports organizations at grass-root level is the basic condition for fulfilling people's various demands for sport. There are many sport organizations in Wujin district, such as Sports Federation, Sports Society for Old People, Sports Society for Peasants, Association of Social Sports Instructor and so on for the existing towns (blocks). One or two district-level sports societies of single item was planned in 2014, to further explore the mechanism and growth model of sports federation in towns; in order to make better development and improvement, China should make good use of all the good factors resources in society. At the same time, China should encourage cooperation between sports society and community in developing physical fitness club in communities that meet the needs of people. This year China plans to build 5 such physical fitness clubs at city level and help those who have the condition to build physical fitness club in communities at district level. China will actively promote the development of 14 great morning and evening exercise spots at provincial level, and more than 2 national fit-keeping bicycle and croquet teams will be formed. China will actively promote the covering of social sports organizations and build more than 2 social sports organizations in all administrative villages and communities at Wujin district, at the same time apply to relevant civil affairs departments to put those on record.

Comprehensive Imple mentation of the Policy of School facilities Opening to the Public. In recent years, under the leadership of Wujin District Bureau of Sports, sunshine sports activities has been carried out by all universities, middle schools, high schools and primary schools in this district. All schools and universities have comprehensively deepened the combination of education with sports and have strengthened the development and management of all types of schools at different level with their own characteristics, such as traditional sports schools, schools with sports characteristics, fitness clubs and so on. There are 7 schools that have been named 2013-2016 Traditional Sports Schools in Jiangsu province, the Teenage Fitness Club at Country Level has been built by Hutangqiao Central Elementary School, and the construction of Teenage Fitness Club at Provincial Level has been developed by Wujin District Youth Sports Training School who has declared the National Great Training League of Track and Field for Amateurish Children together with Wujin Senior High School 
in Jiangsu province. At the national track and field match for traditional sports schools, these two schools made joint teams and cooperated with each other, though first took part in the match on behalf of Jiangsu province, they won the first place in the B team for women and the third place in group match. This year, more sports facilities in schools universities, enterprises and institutions in this district will be promoted to open to the public. The government together with the Bureau of Sports in Wujin district will work together to strengthen the open of school and university sports facilities in urban areas, and to make sure that by the end of this year, more than $95 \%$ of those facilities are opened to the public.

Building of City's “Sports Card" by Great Sports Match. In recent years, Wujin District has given a new image to the public through undertaking numbers of national and international sports matches, such as Chinese Dagon Boat Competition at Wujin Taihu Lake Bay, China Wujin Opens in Hockey, the International Cycling Race around Taihu Lake, China Table Tennis Super League Tournament, China Opens in Fire Balloon, World Half Marathon surrounding the West Taihu Lake, which all helps to raise the influence, popularity and reputation of Wujin. In the year 2014, all the related departments made persistent efforts to make the "Sports Card" of Wujin, and planned to hold national or international game for more than 3 times. It is also an important thing to build the brand sports activities, such as international cycling race around Taihu Lake, Chinese Dagon Boat Competition, China opens in Fire Balloon. In this district, sports games or activities at district level will be held, teenage games will become more than 20 times, at the same time, mass basketball games, football games and volleyball games are plan to be held, and China will work to ensure that there will be more than 10 teams join in each game.

Further Enhance ment of Front-line Sports Backbone Team. In the last few years, as the arduous effects have been made by its government and society, social sports guiding office have been formed in all the towns and blocks in Wujin district. There are special fees and special people in charge of it. Their main work is to train, instruct and administrate the sports instructors. People in Wujin district works well and has experience in this aspect and is considered as Wujin Model by people of the same trade in Jiangsu province. What's more, it has shown great social influence. In 2014, the team of sports backbones in Wujin district will become larger, no less than 130 sports instructors are planned to be trained for free among whom 25 are at first level or above, 40 at second level. All the newly appointed undergraduate village officials will be qualified as sport instructors, and the work of registration of sports instructors in this district at "sports management online" will be completed by the end of this year. On the afternoon of May 29th, a meeting to promote the construction of demonstration area for public sports service system in Jiangsu province and implement the construction of urban and rural "10-minute sports area" was held. This meeting deeply analyzed the new condition and situation faced with in their work and also made arrangement for their key tasks and goal in the following period, which all helped to lay a solid policy foundation for improving national fitness project in Wujin and for providing better and more convenient public sports service to the public.

\section{Conclusions}

In modern society, citizen's lifestyle has been influenced by the development of that city. Public sports service system aiming at pursuing people's development in an all-around way and raising quality of life has raised more concern. In recent years, motivated by reform and opening up and innovation driven development, new progress has made in sports affairs of Jiangsu Province, and the mass sports, competitive sports and sports industry all develop comprehensively. In order to meet people's growing sports needs and explore new methods and measures of the development for sports affairs in China, and based on the leadership of the government, coordination of the departments, participation of the whole society, Wujin district has advanced the development of basic public sports service system in an orderly manner. Meanwhile, it has worked actively to improve the meaning of public sports service, make the government, market and society fully play its role. At the same time, 
expand supply of public sports service and accelerate urban and rural integrated development of basic public sports service system with its own characteristics and perfect function. In this case, to make sport in people's livelihood and ensure all can enjoy the fitness bring by sports, the study of building demonstration area for public sports service system in Wujin district can help to provide experience and reference for the development of China's public sports service system by playing its typical pilot, influential and driving role. And those all can effectively help to promote scientific development of public sports service system.

\section{References}

[1] General Administration of Sport. The 12th Five-Year Plan of Sports Development [EB/OL]. [2011-4-1]. http://www. sport.gov.cn/n16/n1077/n1467/n1843577/1843747.htm1

[2] General Administration of Sport. Cooperative Agreement on Construction of Public Sports Service System Demonstration Plot between General Administration of Sport and the People's Government of Jiangsu Province. [EB/OL]. [2014-1-1].http://www.sport.gov.cn/n16/n1077/n1227/4934895.html

[3] The General Office of the People's Government of Jiangsu Province. The "12th Five-Year" Plan of Basic Public Service System in Jiangsu Province [EB/OL]. [2013-11-27].http//www. wjty.gov.cn/pub/show2009.asp?cid=94584

[4] Tang Jilan. Study on Publicness of Public Sports [J].Journal of Tianjin University of Sport, 2010, 25(6)

[5] Xun Changdian. Review on Development of China's Public Sports Service [J]. Journal of Physical Education, 2009,(06):20-24

[6] Fan Bingyou. Theoretical Framework and System Structure of Public Sports Service. [J]. Journal of Physical Education, 2009, (06):14-19

[7] Mou Chunlei. On the Reform Orientation of China's Public Sports Service in Public Value [J]. Sport and Science, 2014, 35(4)

[8] Liu Qingshan. Review on the Study of China's Public Sports Service System [J]. Journal of Shanghai University of Sport, 2008, (03):24-26

[9] Wang Wenqi. Institutional Poverty and Innovation on China's Public Sports Service System in Rural Area [J]. Journal of Physical Education, 2014, (5)

[10] Tang Jilan. Analysis on Current Condition of the Equalization of Basic Public Sports Service at Gross-root Level [J]. Sports Cultural Guide, 2013, (11) 